\title{
Crystallisation, thermal analysis and acetal protection activity of new layered Zn(II) hybrid polymorphs
}

\author{
Salem Saïd, ${ }^{a}$ Houcine Naïlia and Raquel P. Herrera ${ }^{b}$ \\ Two new polymorphic mononuclear complexes, with analogous structural formula $\left(\mathrm{C}_{6} \mathrm{H}_{9} \mathrm{~N}_{2}\right)_{2}\left[\mathrm{Zn}\left(\mathrm{H}_{2} \mathrm{O}\right)_{6}\right]\left(\mathrm{SO}_{4}\right)_{2} \cdot 2 \mathrm{H}_{2} \mathrm{O}$, of \\ Zinc(II) templated by 2-amino-6-methylpyridinium ligand have been discovered. These polymorphic hybrid crystals, which \\ differ only in terms of their crystal structures, were prepared in one-step synthesis under ambient conditions and \\ investigated for their thermal and catalytic properties. Single-crystal X-ray diffraction of the obtained materials revealed \\ that polymorphs 1 and $\mathbf{2}$ crystallise in the triclinic system, space group $P \overline{\mathbf{1}}$. In an effort to further explore the form \\ diversity of these compounds, the structural arrangements and the intermolecular interactions such as hydrogen-bonding \\ and $\pi \cdots \pi$ interactions are discussed from which supramolecular assembly was formed. Meanwhile, these new polymorphic \\ forms can be described as the stacking of 3D layers where the interlayer distances are 13.23 and $12.59 \AA$ for $\mathbf{1}$ and $\mathbf{2}$, \\ respectively. The thermal behaviour of the precursors checked by TG-DTA analysis for both zinc sulfate polymorphs and \\ variable temperature powder X-Ray diffraction (VT-PXRD), show successive intermediate crystalline anhydrous phases \\ upon dehydration in $\mathbf{1}$. The catalytic activity of both polymorphic structures has been tested in the acetalisation reaction \\ of aldehydes as a benchmark process. Interestingly, both complexes showed excellent activity with almost total conversion \\ in many examples and using $\mathrm{MeOH}$ as solvent and as the unique source of acetalisation.
}

\section{Introduction}

A very large number of solid substances can appear under various phases if the environmental growth conditions enable it. These phases can be polymorphic forms, microcrystalline solids or amorphous materials. We will focus hereafter completely on polymorphism, in which each polymorphic variety has the same chemical composition, however presents variations in the internal arrangement of atoms, ions or molecules that constitute the crystal lattice. The phenomenon of polymorphism - the ability of a compound to crystallise in more than one crystal structure - has been the subject of growing interest. ${ }^{1}$ Polymorphism ${ }^{2-5}$ is one of the most fascinating phenomena, that confers great value in pharmaceutical industry, on solid state chemistry and crystal engineering. Indeed, it is a "difficult" phenomenon studied for many decades mainly, and separately, in the fields of organic and inorganic chemistry. Hence, it is the property of a substance to exist in different crystalline phases resulting from different arrangements of the molecules in the solid state. ${ }^{6}$ In spite of the huge efforts of many scientists, the knowledge about polymorphic complexes is still embryonic. The relationship between the growth of thermodynamically stable (or metastable) crystalline phases and nucleation of the first crystallites is still mysterious. ${ }^{7,8}$ A great number of metal cations and organic entities that can be used to obtain polymorphic compounds make it possible to have potential applications in numerous fields, such as catalysis, biological activities, electromagnetic and optical functions. ${ }^{9-18}$ In a supramolecular sense, polymorphism is the existence of more than one type of network superstructure for the same molecular building blocks. Hence, strong and rigid interactions avoid changes in crystal structures and the formation of different crystalline modifications of one chemical compound. Although polymorphism is a well-known crystallographic phenomenon, ${ }^{19,20}$ no model exists to predict the polymorphic behaviour of chemical compounds. Basically two reasons for polymorphism are distinguishable: (1) the deviation of the molecular arrangement at a minimum of energy or thermodynamic equilibrium and (2) a variety of possible association modes or packing relations of the molecules, i.e. geometric reasons. Recently, it has been shown that the structural study toward the understanding of polymorphism in framework structures can give rise to new insights especially in the role of weak interactions. The non-covalent interactions play an important role in organising structural units. They exert important effects on the organisation and properties of many materials in areas such as biology, ${ }^{21,22}$ crystal engineering ${ }^{23,24}$ and material science. ${ }^{25,26}$ However, yet it is still a hard task to predict and control the crystal structures of such compounds. Then, intermolecular interactions are the essence of supramolecular chemistry, and the field of crystal supramolecularity seeks to understand intermolecular interactions by analyses of crystal packing. One of the compelling reasons for research in this area is to look for newer structures and in some cases to investigate the close structural relationships and possible transformations between the structures within a family of compounds. ${ }^{27}$

A number of papers have studied the structure-property relationships of polymorphic forms. Then, the aim of this paper is essentially twofold: (i) to take polymorphism from the more traditional field of organic chemistry to the neighbouring area of supramolecular chemistry, and (ii) to characterise and discuss the chemical preparation, the catalytic properties, the thermal behaviour and the crystallographic description of two new hybrid polymorphic frameworks of $\mathrm{Zn}$ (II) sulfate templated by 2-amino-6-methylpyridinium. The hope is to stimulate research in this exciting field.

\section{Experimental}

\section{Materials}

In order to obtain crystals of high quality, purification of starting materials was found to be an important step and hence, the recrystallised salts were used for the growth of crystals of the studied materials. All chemicals and solvents were purchased from Sigma- 
Aldrich and it was further purified by repeated re-crystallisation processes for three times using de-ionised water as the solvent.

\section{Synthesis}

Single crystals of the polymorphic phases were grown by solution method with slow evaporative crystallisation technique at room temperature $\left(30{ }^{\circ} \mathrm{C}\right)$. Therefore, the concomitant polymorphism occurs in the same crystallization vial, from the same solution under the same conditions. Then the saturated solution was prepared and it was constantly stirred for about 2 hours using a magnetic stirrer and was filtered using 4 micro Whatmann filter papers. Then, the filtered solution was kept in a borosil beaker covered with a porous paper and kept in a dust-free atmosphere. After the successful dissolving of the chemical species, two kinds of crystals were harvested after a period of about two weeks. In addition, the development of a process used for obtaining a given polymorphic variety can be considered only if the data of thermodynamic and kinetic conditions enable it. These concomitant polymorphs, although rare, were prepared in one-step synthesis. Therefore, $1 \mathrm{mmol}$ of $\mathrm{Zinc}(\mathrm{II})$ sulfate heptahydrate $\left(\mathrm{ZnSO}_{4} \cdot 7 \mathrm{H}_{2} \mathrm{O}\right)$ and $2 \mathrm{mmol}$ of 2-amino-6-methylpyridine $\left(\mathrm{C}_{6} \mathrm{H}_{8} \mathrm{~N}_{2}\right)$ were each dissolved in $10 \mathrm{~mL}$ of distilled water. The $\mathrm{Zn}$ (II) salt solution was then added slowly to the ligand solution. The $\mathrm{pH}$ of the resulting solution was adjusted between 2 and 3 by dropwise addition of concentrated sulfuric acid $\left(\mathrm{H}_{2} \mathrm{SO}_{4}\right)$ until the solution becomes clear. Thereby, with the aim of preventing any precipitation, the solution was filtered to remove any solids. polymorph $\mathbf{1}$ appeared as colourless needles crystals and polymorph $\mathbf{2}$ was found to have a colourless block morphology. The crystals are stable for a long-time in normal conditions of temperature and humidity.

\section{Single-Crystal X-ray Diffraction}

Details of crystallographic data collection and refinement parameters for polymorphic complexes $\mathbf{1}$ and $\mathbf{2}$ are given in Table 1.

Table 1. Crystallographic data and structure refinement parameters for polymorphs $\mathbf{1}$ and $\mathbf{2}$.

\begin{tabular}{|c|c|c|}
\hline Structural parameter & Polymorph 1 & Polymorph 2 \\
\hline formula & $\left(\mathrm{C}_{6} \mathrm{H}_{9} \mathrm{~N}_{2}\right)_{2}\left[\mathrm{Zn}\left(\mathrm{H}_{2} \mathrm{O}\right)_{6}\right]\left(\mathrm{SO}_{4}\right)_{2} \cdot 2 \mathrm{H}_{2} \mathrm{O}$ & $\left(\mathrm{C}_{6} \mathrm{H}_{9} \mathrm{~N}_{2}\right)_{2}\left[\mathrm{Zn}\left(\mathrm{H}_{2} \mathrm{O}\right)_{6}\right]\left(\mathrm{SO}_{4}\right)_{2} \cdot 2 \mathrm{H}_{2} \mathrm{O}$ \\
\hline formula weight $\left(\mathrm{g} \mathrm{mol}^{-1}\right.$ ) & 620 & 620 \\
\hline Temperature (K) & $100(2)$ & $100(2)$ \\
\hline Crystal system & Triclinic & Triclinic \\
\hline Space group & $P \overline{1}$ & $P \overline{1}$ \\
\hline$a(\AA)$ & $7.3614(18)$ & $7.3453(18)$ \\
\hline $\mathrm{b}(\AA ̊)$ & $13.234(4)$ & $12.594(4)$ \\
\hline$c(\AA)$ & $13.939(4)$ & $20.074(6)$ \\
\hline$\alpha\left({ }^{\circ}\right)$ & $106.77(4)$ & $80.60(3)$ \\
\hline$\beta\left(^{\circ}\right)$ & $104.90(4)$ & $83.38(3)$ \\
\hline$\gamma\left({ }^{\circ}\right)$ & $98.84(4)$ & $89.56(3)$ \\
\hline$V\left(\AA^{3}\right)$ & $1217.8(8)$ & $1819.7(9)$ \\
\hline $\mathrm{Z}$ & 2 & 3 \\
\hline Diffractometer & Xcalibur, Ruby & Xcalibur, Ruby \\
\hline Programs system & SHELXL-2013 and SHELXS-97 & SHELXL-2013 and SHELXS-97 \\
\hline Absorption correction & Analytical & Analytical \\
\hline$\rho_{\text {cal }}\left(\mathrm{g} \mathrm{cm}^{-3}\right)$ & 1.691 & 1.697 \\
\hline Crystal size $\left(\mathrm{mm}^{3}\right)$ & $0.32 \times 0.23 \times 0.11$ & $0.35 \times 0.20 \times 0.11$ \\
\hline Crystal color/shape & needle, colorless & block, colorless \\
\hline$\mu\left(\mathrm{mm}^{-1}\right)$ & 1.262 & 1.266 \\
\hline$\theta$ range (deg) & $\theta_{\min }=2, \theta_{\max }=31$ & $\theta_{\min }=2, \theta_{\max }=29$ \\
\hline \multirow[t]{3}{*}{ hkl range } & $-9 \leq h \leq 10$ & $-8 \leq h \leq 9$ \\
\hline & $-18 \leq k \leq 9$ & $-16 \leq k \leq 16$ \\
\hline & $-14 \leq \mathrm{I} \leq 19$ & $-26 \leq 1 \leq 25$ \\
\hline No. of reflection collected & 7447 & 9293 \\
\hline No. of independant reflection & 5599 & 6332 \\
\hline$F(000)$ & 648 & 972 \\
\hline R1 & 0.0299 & 0.0407 \\
\hline wR2 & 0.0757 & 0.1078 \\
\hline GooF & 1.067 & 1.038 \\
\hline No. param. & 321 & 478 \\
\hline Transmission factors & $\mathrm{T}_{\min }=0.672 ; \mathrm{T}_{\max }=0.796$ & $\mathrm{~T}_{\min }=0.708 ; \mathrm{T}_{\max }=0.897$ \\
\hline Largest difference map hole & $\Delta \rho_{\min }=-0.480, \Delta \rho_{\max }=0.430$ & $\Delta \rho_{\min }=-0.580, \Delta \rho_{\max }=0.580$ \\
\hline
\end{tabular}

Both polymorphs were mounted onto glass fibre and cooled to low temperatures. Data were performed on a, Xcalibur Ruby, diffractometer with graphite monochromatised Mo ka radiation $(\lambda$ $=0.71073 \AA$ A), using an Oxford Cryosystems cooler. Data collection, cell refinement, data reduction and analysis were carried out with CrysAlisPRO. ${ }^{28}$ Analytical absorption correction was applied to the data with the use of CrysAlisRED ${ }^{28}$. Structures of $\left(\mathrm{C}_{6} \mathrm{H}_{9} \mathrm{~N}_{2}\right)_{2}\left[\mathrm{Zn}\left(\mathrm{H}_{2} \mathrm{O}\right)_{6}\right]\left(\mathrm{SO}_{4}\right)_{2} \cdot 2 \mathrm{H}_{2} \mathrm{O}$ were solved with direct methods using SHELXS-97, ${ }^{29}$ and refined by a full-matrix least squares technique with SHELXL-2013 ${ }^{30}$ with anisotropic thermal parameters for all non $\mathrm{H}$-atoms. All $\mathrm{H}$-atoms were initially located in difference Fourier maps, and in the final refinement cycles the $\mathrm{C}$-bonded $\mathrm{H}$ 
atoms were placed in calculated positions, with $\mathrm{C}-\mathrm{H}=0.95 \AA$, and refined with a riding model with $\mathrm{U}_{\text {iso }}(\mathrm{H})=1.2 \mathrm{U}_{\text {eq }}(\mathrm{C})$. The $\mathrm{O}$ - and $\mathrm{N}$ bonded hydrogen atoms were located from difference maps and treated with $\mathrm{U}_{\text {iso }}(\mathrm{H})=1.5 \mathrm{U}_{\text {iso }}(\mathrm{O})$ and $\mathrm{U}(\mathrm{H})=1.2 \mathrm{U}_{\text {iso }}(\mathrm{N})$. All figures were made using DIAMOND program. ${ }^{31}$

\section{Thermal analysis measurements}

TGA-DTA measurements of complexes $\mathbf{1}$ and $\mathbf{2}$ were performed using a 'SETSYS Evolution' (Pt crucibles, $\mathrm{Al}_{2} \mathrm{O}_{3}$ as a reference) instrument, under air flow (100 $\mathrm{ml} / \mathrm{min})$, for any compound, with a heating rate of $5{ }^{\circ} \mathrm{C} \mathrm{min}^{-1}$ up to $600{ }^{\circ} \mathrm{C}$. Variable temperature powder X-ray diffraction (VT-PXRD) analysis was carried out using a $\theta-\theta$ Bruker AXS D8 Advance powder diffractometer, equipped with a high-temperature Anton Paar HTK1200 oven camera and a LynxEye detector. Powder patterns were collected sequentially upon heating at $21.6^{\circ} \mathrm{C} \mathrm{h}^{-1}$ up to $450{ }^{\circ} \mathrm{C}$, with the monochromatised CuKa1 radiation $(\lambda=1.5406 \AA)$. To ensure satisfactory counting statistics, counting times of $20 \mathrm{~min} /$ pattern were selected for the thermal decomposition of the precursors, so that any pattern could be collected within a temperature range of $7.2^{\circ} \mathrm{C}$.

\section{General catalytic procedure for the synthesis of acetals 4}

Complex 1 (8 mg, $0.01292 \mathrm{mmol}$ ) and aldehydes 3a-1 $(0.323 \mathrm{mmol})$ were dissolved in $\mathrm{MeOH}(0.25 \mathrm{ml})$ in a test tube. The resulting mixture was stirred at $40{ }^{\circ} \mathrm{C}$ during $24 \mathrm{~h}$. The reactions were monitored by thin-layer chromatography. The yield of the reaction is given by ${ }^{1} \mathrm{H} N M R$.

\section{Results and discussion}

\section{Description of Crystal Structures of Polymorphs $\left(\mathrm{C}_{6} \mathrm{H}_{9} \mathrm{~N}_{2}\right)_{2}\left[\mathrm{Zn}\left(\mathrm{H}_{2} \mathrm{O}\right)_{6}\right]\left(\mathrm{SO}_{4}\right)_{2} \cdot 2 \mathrm{H}_{2} \mathrm{O}$}

The molecular geometry in the two polymorphic structures 1 and $\mathbf{2}$ is very similar. However, the packing arrangement is completely different, thus showing polymorphism. It is noteworthy that the following driving forces, which influence the mode of packing, are to be considered as possible reasons for the polymorphism here: (a) hydrogen bonding and van-der Waals (vdW) forces (b) tendency to achieve a closer packed structure, including $\pi \cdots \pi$ stacking, and (d) type of solvent used in the crystallisation process. ${ }^{32,33}$ The hybrid polymorphs described within this work crystallise in the centrosymmetric space groups $P \bar{Y}$. Polymorph 1 consists of two zinc cations octahedrally coordinated by six water molecules, two isolated sulfate anions, two 2-amino-6-methylpyridinium cations and two free $\mathrm{H}_{2} \mathrm{O}$ units (Figure 1).

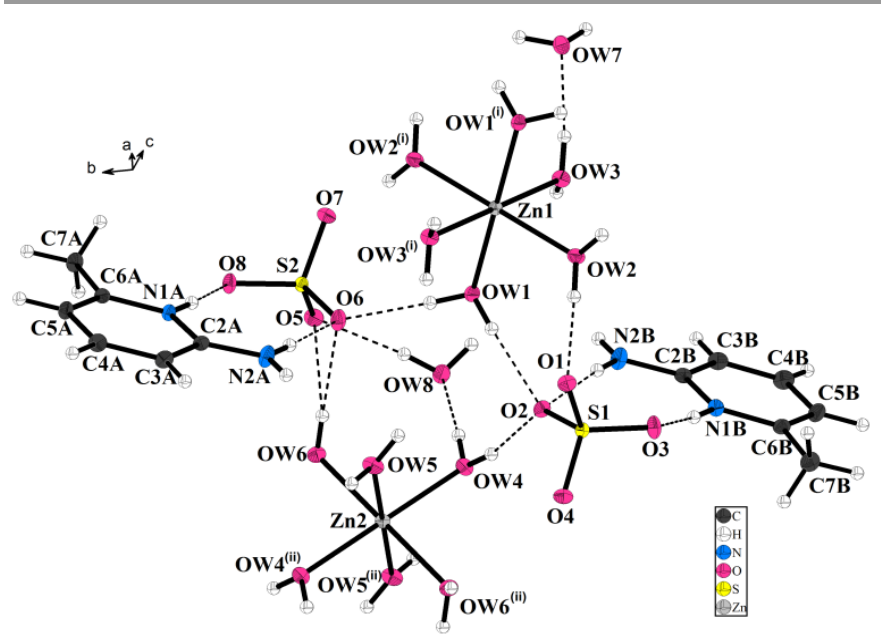

Fig. 1 Part of the crystal structure of polymorph 1 at $100 \mathrm{~K}$ showing the asymmetric unit and atom-numbering scheme. Displacement ellipsoids are drawn at the $50 \%$ probability level. Hydrogen bonds are represented by dashed lines, [Zn1 and Zn2 octahedra are completed by symmetry, symmetry code: $i$ $=1-x, 1-y, 1-z$ and $i \mathrm{i}=-x, 1-y,-z$; respectively].

The zinc cations in $\mathbf{1}$ are located in special positions on crystallographic inversion centres and each is coordinated by six oxygen atoms from water molecules of which three are crystallographically independent. While, the protonated organic species, the sulfate tetrahedron and the uncoordinated water molecules are located in general positions. In contrast, in the structure of polymorph 2, each zinc octahedron is surrounded by six water molecules to form two hexaaquazinc(II) complexes, three sulfate tetrahedra, three protonated 2-amino-6-methylpyridinium cations and three uncoordinated water molecules (Figure 2).

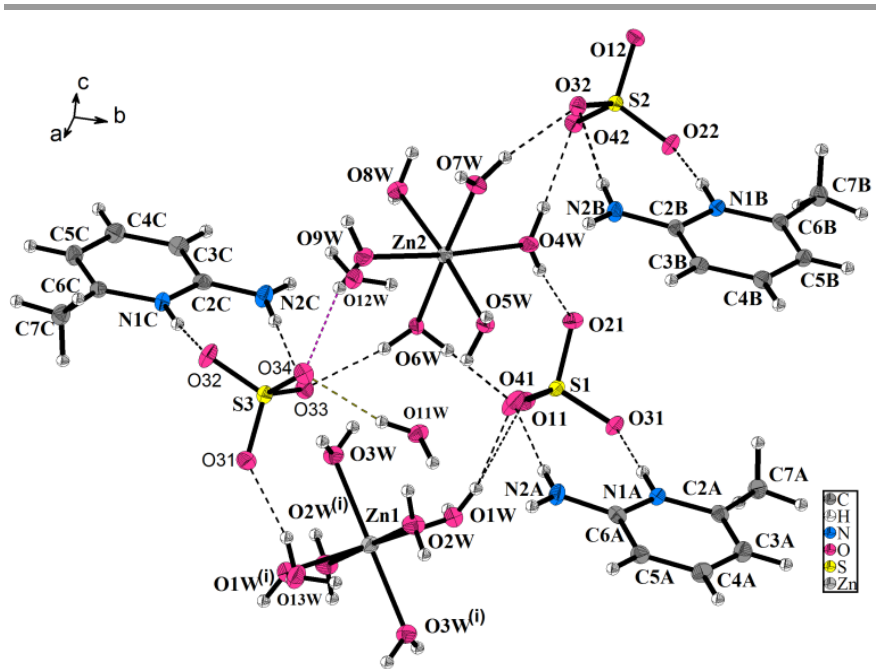

Fig. 2 Part of the crystal structure of polymorph 2 at $100 \mathrm{~K}$ showing the asymmetric unit and atom-numbering scheme. Displacement ellipsoids are drawn at the $50 \%$ probability level. Hydrogen bonds are represented by dashed lines, [Zn1 octahedron is completed by symmetry, symmetry code $i=1-x$, $1-y, 1-z]$. 
The $\mathrm{Zn}(1)$ atom in polymorph $\mathbf{2}$ lying at the special position on an inversion center, is coordinated by six water molecules from which three are crystallografically independent. However, all the other atoms occupy general positions. The sulfate anions play a major role in the formation of the 3D supramolecular arrangement in the studied phases. These tetrahedra are stacked along the crystallographic a-axis. Hence, tie between protonated amines and $\mathrm{Zn}$-complexes is formed by means of $\mathrm{N}-\mathrm{H} \cdots \mathrm{O}(\mathrm{S})$ and $\mathrm{OW}-\mathrm{HW} \cdots \mathrm{O}(\mathrm{S})$ hydrogen bonds. Within the sulfate tetrahedra, $\mathrm{S}-\mathrm{O}$ bond distances range between $1.4606(2)$ and $1.4957(3) \AA$. The O-S-O bond angles fall in the range $107.223(8)-111.00(11)^{\circ}$. X-ray analyses reveal that both structures $\mathbf{1}$ and $\mathbf{2}$ are mononuclear complexes. The overall geometry around zinc(II) ions, in the studied materials, are best described as a slightly distorted octahedon and are similar with those described in previous works. Selected bond lengths and angles are collected in tables S1 and S2 (supporting information).

In 1, the zinc-oxygen distances are between 2.0742(3) to 2.1119 (3) $\AA$ and the $\mathrm{O}-\mathrm{Zn}-\mathrm{O}$ bond angles are in the range $87.917(5)$ to $179.993(6)^{\circ}$. Similarly, the $\mathrm{Zn}-\mathrm{O}$ bonds in 2 range from 2.0461(1) to 2.1110(3) $\AA$ and the $\mathrm{O}-\mathrm{Zn}-\mathrm{O}$ bond angles vary from $87.281(7)$ and $175.480(7)^{\circ}$, which is similar to other organically templated metal sulfates. Indeed, the intermolecular $\mathrm{Zn}$ "...Zn" distance in $\mathbf{2}$ is considerably longer than that found in 1 (7.3453(18) $\AA$ and 6.9949(30) $\AA$, respectively). These distances are somewhat longer than those found in previously published papers of $\mathrm{Mn}^{\prime \prime}$ and $\mathrm{Co}^{\prime \prime} .^{34}$ This difference in the metal-metal distance is likely due to the size and the shape of the amino groups and the radii of transition metal cations. In the structures of polymorphs $\mathbf{1}$ and $\mathbf{2}$ the supramolecular character and the molecular arrangement are insured and built from $\left[\mathrm{Zn}^{\prime \prime}\left(\mathrm{H}_{2} \mathrm{O}\right)_{6}\right]^{2+},\left(\mathrm{SO}_{4}\right)^{2-}$, protonated $\left(\mathrm{C}_{6} \mathrm{H}_{9} \mathrm{~N}_{2}\right)^{+}$ions and uncoordinated water molecules linked together by an extensive three-dimensional $\mathrm{H}$-bonding network (Tables S3 and S4 in supporting information).

The inorganic sheets are parallel to the $(a, c)$ plane and consist of isolated metallic octahedral of hexaaquazinc (II) cations, sulfate tetrahedral and free water molecules. Therefore, the uncoordinated water ties between inorganic molecules are formed via hydrogen bonding, which can be seen as a bridge between the neighbour entities within the inorganic layers. Indeed, they participate in two types of hydrogen bonds OW$\mathrm{H} \cdots \mathrm{O}$ and $\mathrm{OW}-\mathrm{H} \cdots \mathrm{OW}$ as donor or acceptor, respectively as illustrated in Figures 3 and 4.

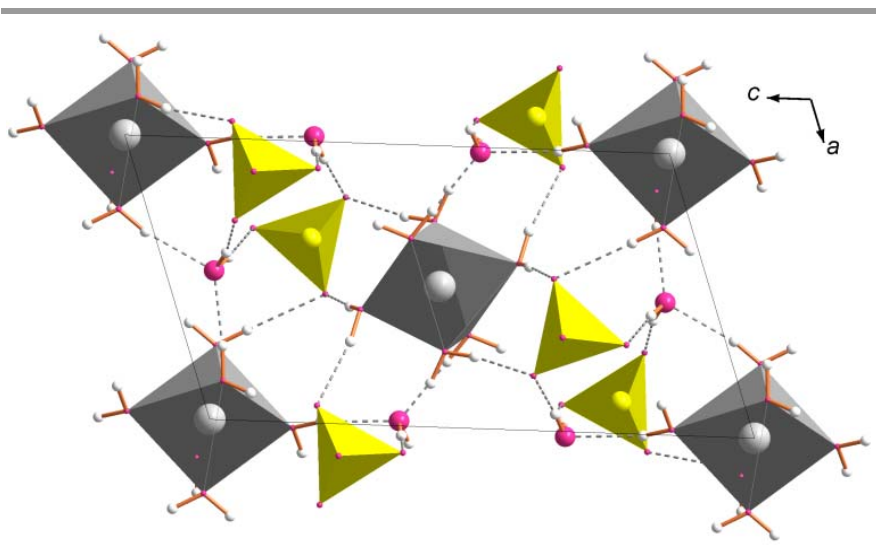

Fig. 3 Supramolecular aspect of hydrogen bonding between the inorganic entities within the mineral layer of polymorph 1.

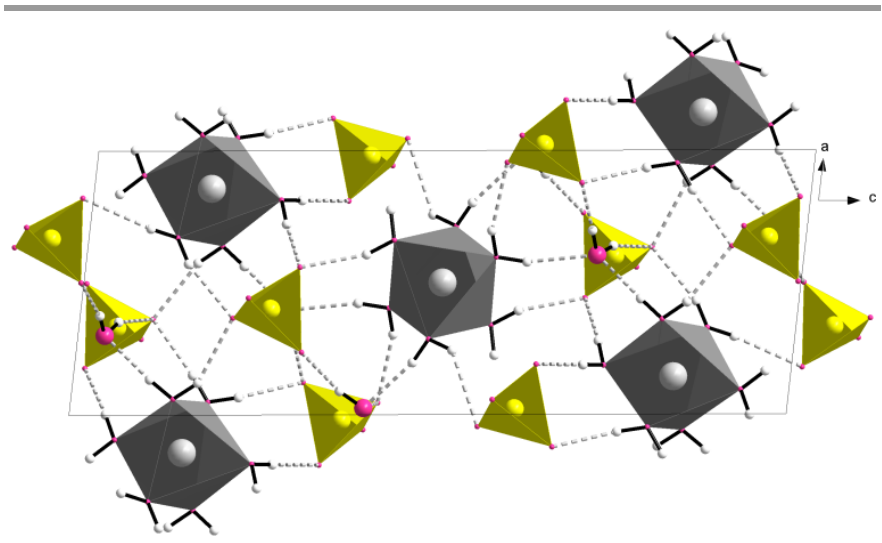

Fig. 4 Supramolecular aspect of hydrogen bonding between the inorganic entities within the mineral layer of polymorph $\mathbf{2}$.

Therefore, they play a subordinate role in cohesion and stabilizing the structures. In addition, the supramolecular crystal structures of $\mathbf{1}$ and $\mathbf{2}$ are built from alternatively arranged inorganic and organic layers along the crystallographic b-axis (Figures 5 and 6). 


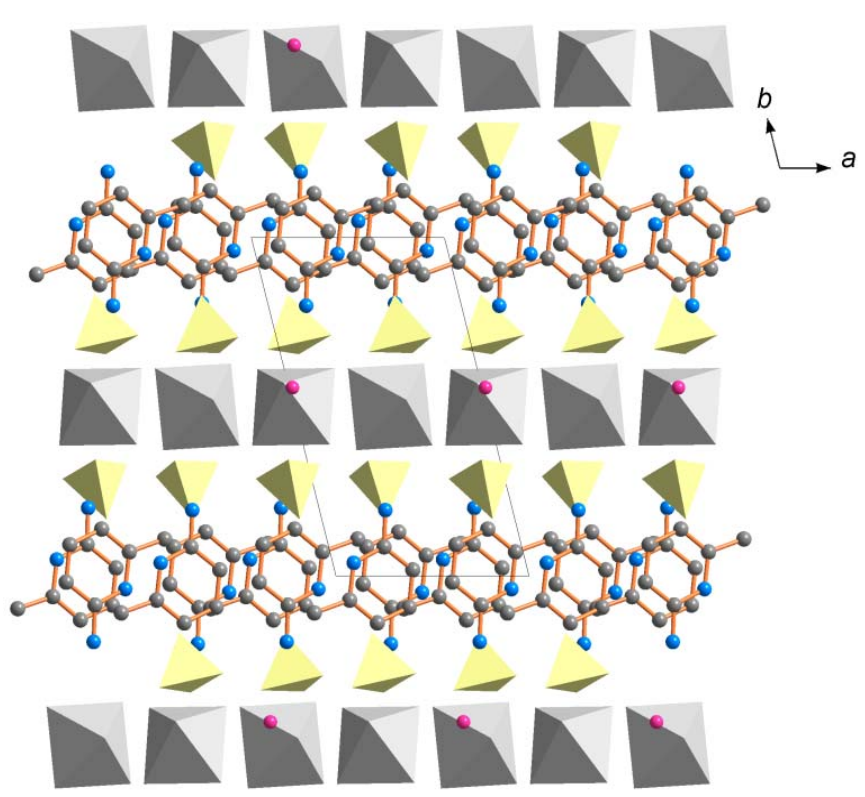

Fig. 5 Projection of the structure along the crystallographic caxis in polymorph $\mathbf{1}$, showing the lamellar character and the stacking along the a-axis (hydrogen atoms are omitted for clarity).

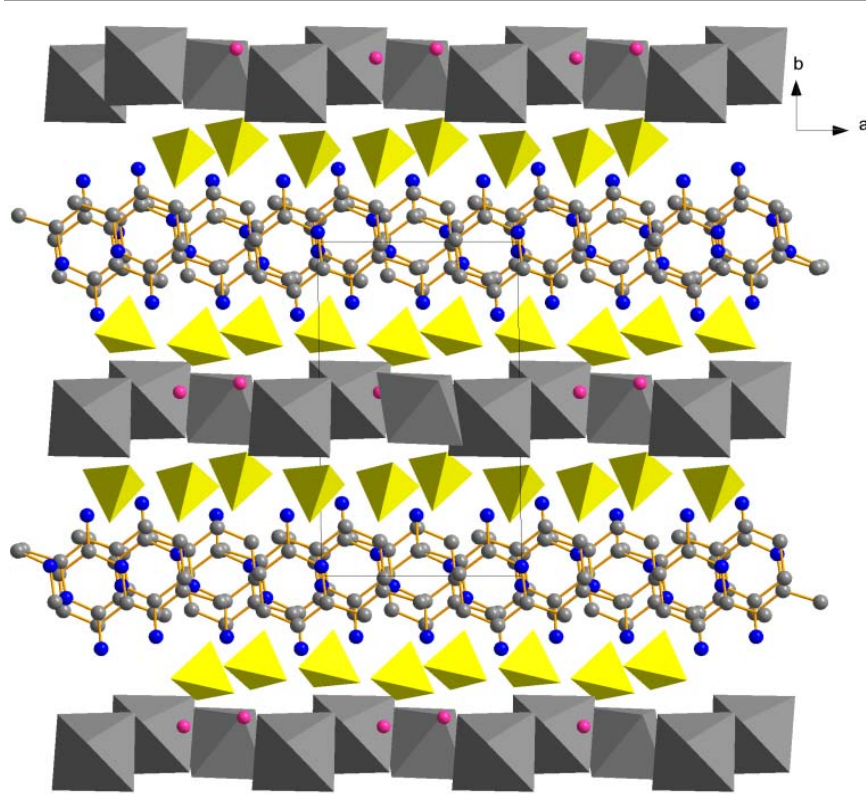

Fig. 6 Projection of the structure along the crystallographic caxis in polymorph $\mathbf{2}$, showing the lamellar character and the stacking along the a-axis (hydrogen atoms are omitted for clarity).

The interlayer spaces between two mineral layers in polymorphs $\mathbf{1}$ and $\mathbf{2}$ are of 13.23(4) and 12.59(4) $\AA$, respectively. Indeed, these distances correspond to the values of the $b$ unit cell parameters. The interlamellar distance is filled with organic entities that form chains through $\pi \cdots \pi$ interactions. In the title polymorphs, the organic sheets are formed by the protonated amine 2-amino-6-methypyridinium.
The pyridine rings of neighbouring molecules interact with each other via $\pi \cdots \pi$ stacking. The centroid $\cdots$ centroid distances fall within two ranges: $3.519(3)$ and $3.779(2) \AA$. The $\pi \cdots \pi$ interactions in $\mathbf{1}$ and $\mathbf{2}$ are of the parallel-displaced configurations (Figures 7 and 8). ${ }^{35}$

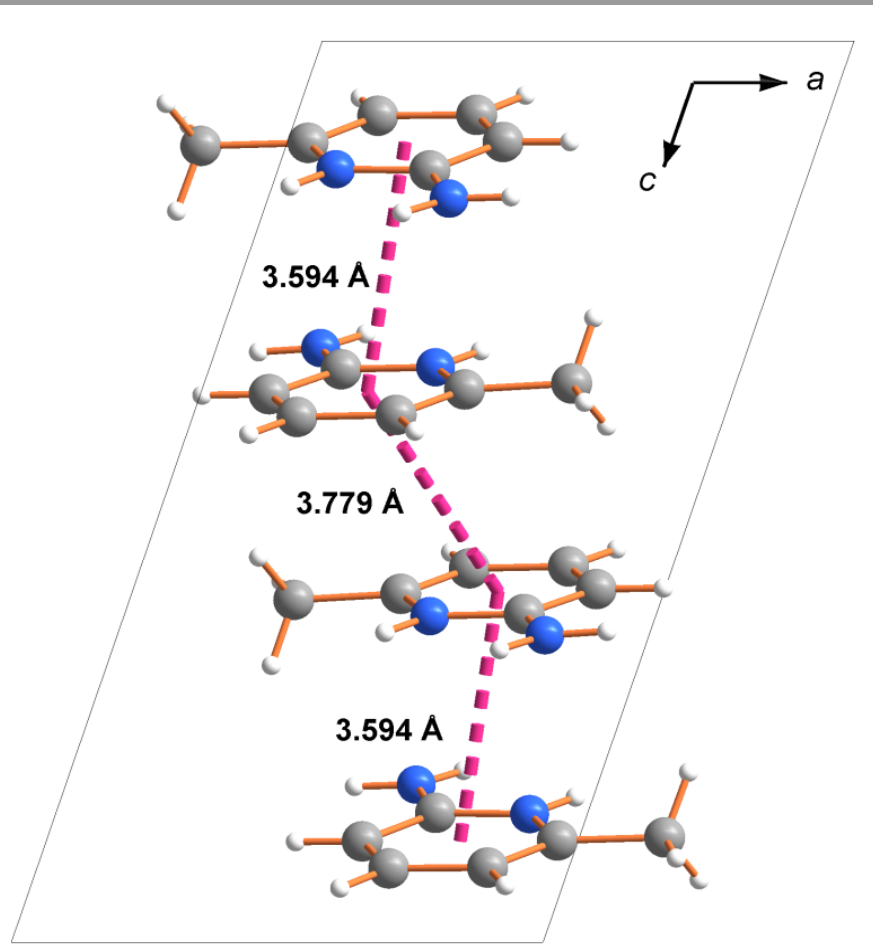

Fig. 7 Offset-face-to-face interactions motifs $(\pi \cdots \pi$ stacking, broken lines) in the cation chains along the crystallographic $b$ axis in 1. 


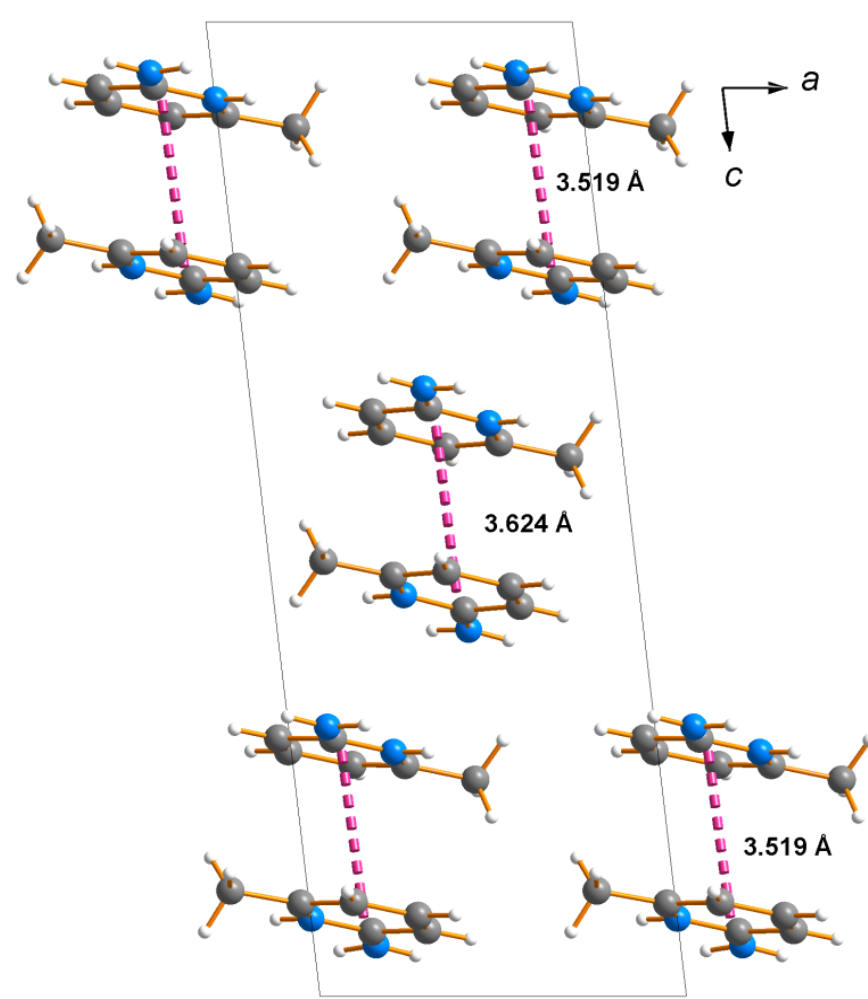

Fig. 8 Offset-face-to-face interactions motifs $(\pi \cdots \pi$ stacking, broken lines) in the cation chains along the crystallographic baxis in $\mathbf{2}$.

Hence, each organic cation engages its hydrogen atoms bonded to $\mathrm{N}$ atoms in $\mathrm{N}-\mathrm{H} \cdots \mathrm{O}$ hydrogen bonds and participates in the structure cohesion through intermolecular $\mathrm{H}$-bonds established between the organic and inorganic layers. The aromatic rings of the protonated 2-amino-6methylpyridinium cations are planar. Their characteristics are illustrated in Tables 2 and 3. The cations contain a protonated $\mathrm{N}$ atom in the pyridine rings. More specifically, protonation of the nitrogen atom leads to an increase in the $\mathrm{C}-\mathrm{N}-\mathrm{C}$ angle in comparison with the unprotonated pyridine $\left[116.94(3)^{\circ}\right]$. The observed angles of $\mathrm{C}-\mathrm{N}-\mathrm{C}$ are ranging from $123.228(2)$ to $123.597(2)^{\circ}$. For both polymorphs, the intermolecular $\mathrm{N}-\mathrm{H} \cdots \mathrm{O}$ bonds range from 2.703(3) $\AA$ to 3.156(5) $\AA$ and the OW-
$\mathrm{H} \cdots \mathrm{O} / \mathrm{OW}$ bond lengths vary from 2.688(5) Å to 3.348(4) Å. In addition, $\mathrm{C}-\mathrm{H} \cdots \mathrm{O} / \mathrm{OW}$ are expected to be between $3.232(5) \AA$ and $3.473(4) \AA$. Both the hydrogen bonds and $\pi \cdots \pi$ interactions are required for the formation of the three dimensional supramolecular architecture of the title compounds. In such a way, both can play an overpowering role to understand the connection of the functional units and the lamellar character in the present compounds

\section{Thermal decomposition}

Thermal decomposition of polymorph 1.

Figures 9 and 10 show the TG-DTA curves and the VT-PXRD plot, obtained, respectively, during the decomposition of the polymorph 1.

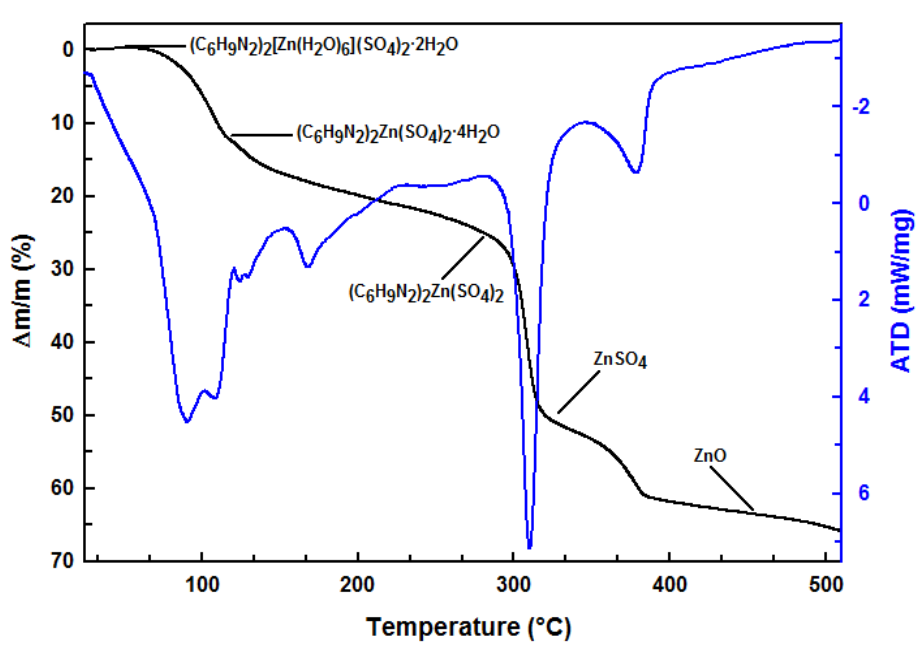

Fig. 9 Simultaneous thermogravimetric analysis and differential thermal analysis scan for polymorph 1 . The scan was performed in flowing air with a ramp rate of $5{ }^{\circ} \mathrm{C} / \mathrm{min}$. 


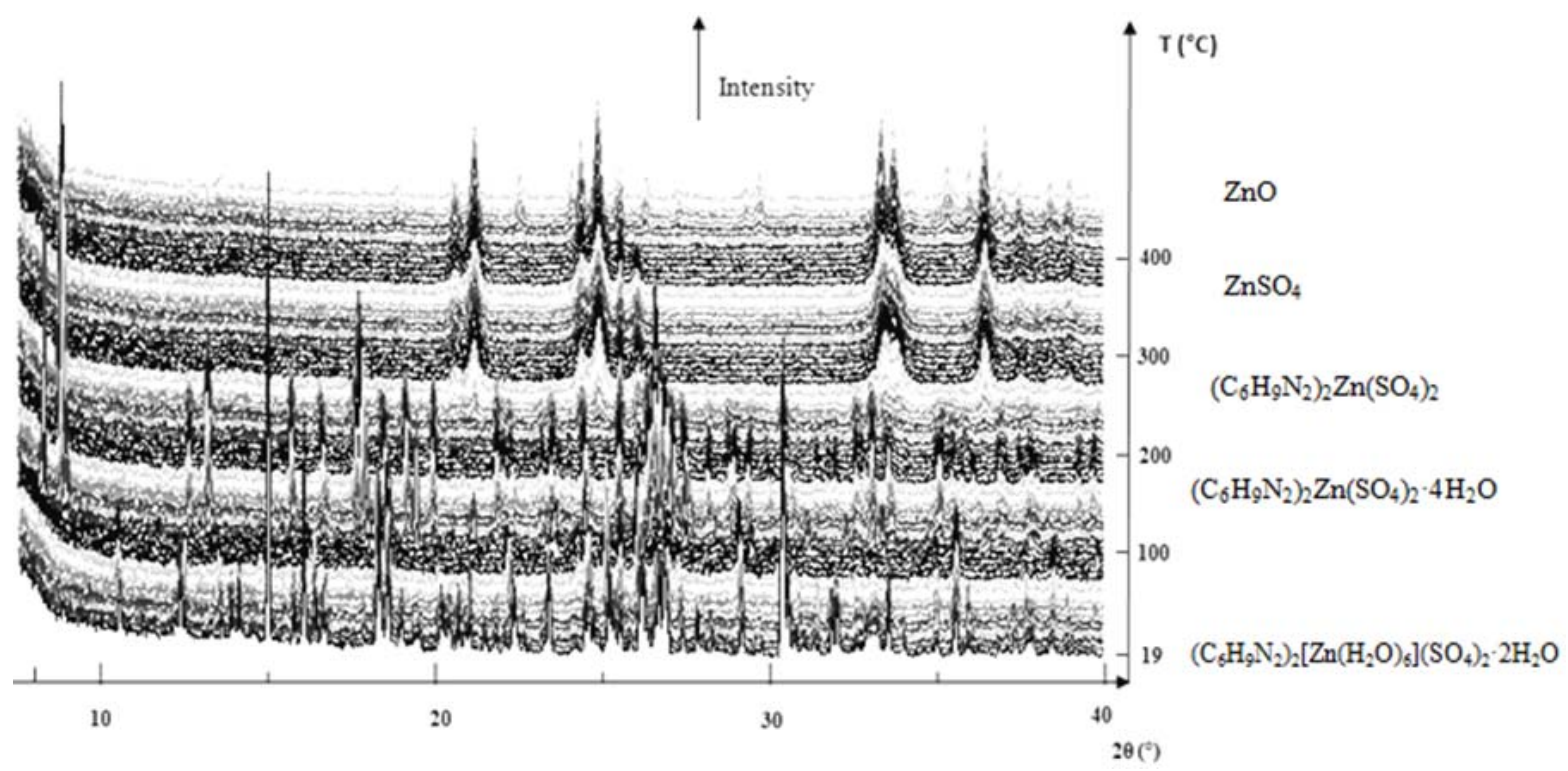

Fig. 10 VT-PXRD patterns for the decomposition of polymorph $\mathbf{1}$ in air, showing the successive crystalline phases.

The studied material remained stable up to $50{ }^{\circ} \mathrm{C}$ and above this temperature a continuous decomposition took place. The first weight loss corresponds to the release of four water molecules (observed weight loss, 11.07\%; calculated weight loss, 10.43\%) giving rise to the compound $\left(\mathrm{C}_{6} \mathrm{H}_{9} \mathrm{~N}_{2}\right)_{2} \mathrm{Zn}\left(\mathrm{SO}_{4}\right)_{2} \cdot 4 \mathrm{H}_{2} \mathrm{O}$. The second transformation corresponds to the release of the last four water molecules (observed weight loss, 21.8\%; calculated weight loss, $23.22 \%)$ leading to the anhydrous phase $\left(\mathrm{C}_{6} \mathrm{H}_{9} \mathrm{~N}_{2}\right)_{2} \mathrm{Zn}\left(\mathrm{SO}_{4}\right)_{2}$. On the DTA curve, the dehydration of the polymorph 1 is accompanied by several endothermic peaks between 90 and $166^{\circ} \mathrm{C}$. Furthermore, the third weight loss of $71.82 \%$, observed on the TG curve in the temperature ranging from 280 to $324{ }^{\circ} \mathrm{C}$, is attributed to the degradation of the organic molecules to form the inorganic phase $\mathrm{ZnSO}_{4}$ (calculated weight loss, 73.96\%). This transformation is accompanied by a very large and intense endothermic peak at 309 ${ }^{\circ} \mathrm{C}$. Then, decomposition goes on and ends by the formation of the zinc oxide $(\mathrm{ZnO})$ as final residue (PDF $\mathrm{N}^{\circ}$ 01-071-2475), which crystallises immediately after $\mathrm{ZnSO}_{4}$ starts to decompose (calculated weight loss, 86.87\%; observed weight loss, $84.51 \%$ ).

The VT-PXRD plot reveals that the precursor, $\left(\mathrm{C}_{6} \mathrm{H}_{9} \mathrm{~N}_{2}\right)_{2}\left[\mathrm{Zn}\left(\mathrm{H}_{2} \mathrm{O}\right)_{6}\right]\left(\mathrm{SO}_{4}\right)_{2} \cdot 2 \mathrm{H}_{2} \mathrm{O}$, is stable until $50{ }^{\circ} \mathrm{C}$ and then transforms into the crystallised phase $\left(\mathrm{C}_{6} \mathrm{H}_{9} \mathrm{~N}_{2}\right)_{2} \mathrm{Zn}\left(\mathrm{SO}_{4}\right)_{2} \cdot 4 \mathrm{H}_{2} \mathrm{O}$, which is stable between $50^{\circ} \mathrm{C}$ and $130{ }^{\circ} \mathrm{C}$. At this temperature, the next transformation starts and leads to the anhydrous and crystallised phase $\left(\mathrm{C}_{6} \mathrm{H}_{9} \mathrm{~N}_{2}\right)_{2} \mathrm{Zn}\left(\mathrm{SO}_{4}\right)_{2}$. The degradation of organic species starts at about $280{ }^{\circ} \mathrm{C}$ and ends above $325^{\circ} \mathrm{C}$, giving rise to a crystallised phase $\mathrm{ZnSO}_{4}$. The last transformation starts at $\sim 450{ }^{\circ} \mathrm{C}$ and corresponds to the formation of $\mathrm{ZnO}$.

\section{Thermal decomposition of polymorph 2.}

The thermal characteristic of polymorph 2 checked by coupled (TGDTA) measurements under flowing air, is shown in Figure 11.

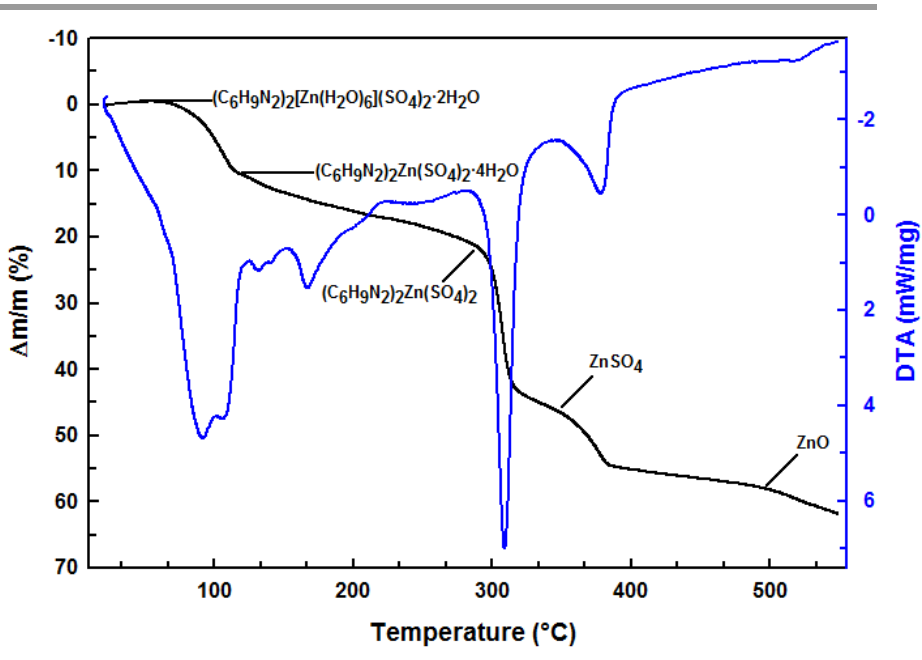

Fig. 11 Simultaneous thermogravimetric analysis and differential thermal analysis scan for polymorph 2 . The scan was performed in flowing air with a ramp rate of $5^{\circ} \mathrm{C} / \mathrm{min}$.

This later demonstrates that the decomposition of the sulfate material takes place through several stages. The first weight loss of $10.43 \%$, observed at temperature range 50 and $109{ }^{\circ} \mathrm{C}$, is ascribed to the release of four $\mathrm{H}_{2} \mathrm{O}$ (calculated weight loss, $11.61 \%$ ). The second transformation, observed between 111 and $180{ }^{\circ} \mathrm{C}$, is attributed to release of the remaining water molecules to form the anhydrous compound $\left(\mathrm{C}_{6} \mathrm{H}_{9} \mathrm{~N}_{2}\right)_{2} \mathrm{Zn}\left(\mathrm{SO}_{4}\right)_{2}$ (observed weight loss, $21.08 \%$; calculated weight loss, $23.22 \%$ ). On the DTA curve, the dehydration of the polymorph $\mathbf{2}$ is accompanied by several endothermic peaks between 90 and $166^{\circ} \mathrm{C}$. The degradation of the organic parts occurs between 280 and $320^{\circ} \mathrm{C}$ leading to the $\mathrm{ZnSO}_{4}$ phase (observed weight loss, $71.82 \%$, calculated weight loss, 73.96\%). This phenomenon is accompanied with a strong endothermic peak on the DTA curve at $308^{\circ} \mathrm{C}$. Above $350{ }^{\circ} \mathrm{C}, \mathrm{ZnO}$ is formed (PDF $\mathrm{N}^{\circ}$ 01-071-2475) (calculated weight loss, 86.86\%; observed weight loss, 84.51\%). 
For each polymorph the physicochemical properties such as melting point, solubility and stability are influenced by the differences in crystal packing and/or the structural conformation. The relative stability of the two polymorphic systems is evidenced. An insight into the interplay around the water molecules, electrostatic and van der Waals ( $v d W$ ) interactions in affecting the thermal properties of the two polymorphs is gained. However, the comparison of the thermal decompositions for these polymorphs showed them to be identical. Interestingly, the dehydration of both forms showed strong similarities despite the differences of their solid state structures. This phenomenon is closely related to the bonding forces that hold the water molecules. On average, calculated $\mathrm{H}_{2} \mathrm{O} \cdots \mathrm{A}$ bond lengths are equal to 1.959(1) and 1.969(2) $\AA$ for the 1and 2-phases, respectively. A similar calculated mean distance is found for all $\mathrm{Zn}-\mathrm{OH}_{2}$ interactions in the case of the 1-form (2.086(3) $\AA$ versus $2.087(1) \AA$ for the 2 one). Therefore, as it can be seen in Table 2 the major intermolecular distances for these molecules are comparable.

Table 2. Average value of intermolecular distances around the water molecules in polymorphs 1 and 2 .

\begin{tabular}{lll}
\hline & Polymorph 1 & Polymorph 2 \\
\hline $\mathrm{d}\left(\mathrm{Zn}-\mathrm{OH}_{2}\right) \AA$ & $2.086(3)$ & $2.087(1)$ \\
$\mathrm{d}\left(\mathrm{H}_{2} \mathrm{O} \cdots \mathrm{A}\right) \AA$ & $1.959(1)$ & $1.969(2)$ \\
\hline
\end{tabular}

\section{Catalytic properties}

The acetalisation of aldehydes is maybe one of the most important approaches for protecting carbonyl groups. ${ }^{36}$ However, although this is an extensive explored process, it still presents some drawbacks. ${ }^{37}$ Sometimes dry conditions and the necessity of removing the in situ formed water is required. In other examples, moisture or air sensibility has been observed. Moreover, hard or aqueous work-up could afford to the decomposition or the rapid hydrolysis of the formed acetal giving back to the carbonyl group. In this context, the design and development of additional catalytic reagents could be of general interest for the development of this field. Despite the great number of reports concerning this synthetic protocol, to the best of our knowledge the use of Zn-based catalysts has been overlooked in the literature until now.

As a part of our ongoing studies to test the effectiveness of new catalysts, we decided to investigate the activity of our both polymorphic species in the acetalisation reaction as a benchmark process.

In order to explore the potential catalytic activity of complexes 1 and $\mathbf{2}$, the model acetalisation reaction between aldehyde $\mathbf{3 a}$ and $\mathrm{MeOH}$ was tested. In a typical reaction, a mixture of aldehyde 3a (0.323 mmol) and $\mathrm{Zn}$ catalysts 1 and 2 (4 mol\%) in $0.25 \mathrm{~mL} \mathrm{MeOH,}$ contained in a glass vessel, was stirred at $40{ }^{\circ} \mathrm{C}$ for $24 \mathrm{~h}$. After this time the reaction crudes were analysed by ${ }^{1} \mathrm{H}$ NMR (Table 3 ).

Table 3. Screening of the acetalisation reaction to obtain $4 a^{38}$<smiles>O=Cc1cccc([N+](=O)[O-])c1</smiles>

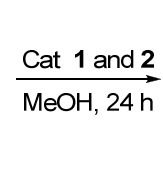<smiles>COC(OC)c1cccc([N+](=O)[O-])c1</smiles>

$4 a$

\begin{tabular}{|c|c|c|c|c|}
\hline Entry & Complex (mol \%) & $\mathrm{MeOH}(\mathrm{mL})$ & Temp $\left({ }^{\circ} \mathrm{C}\right)$ & Yield (\%) \\
\hline 1 & $1(2)$ & 0.25 & r.t. & 56 \\
\hline 2 & $1(4)$ & 0.25 & r.t. & 82 \\
\hline 3 & $1(6)$ & 0.25 & r.t. & 82 \\
\hline 4 & $1(4)$ & 0.50 & r.t. & 33 \\
\hline 5 & 1 (4) & 0.25 & 40 & 93 \\
\hline 6 & $2(2)$ & 0.25 & r.t. & 29 \\
\hline 7 & $2(4)$ & 0.25 & r.t. & 51 \\
\hline 8 & $2(6)$ & 0.25 & r.t. & 38 \\
\hline 9 & $2(4)$ & 0.50 & r.t. & 26 \\
\hline 10 & $2(4)$ & 0.25 & 40 & 90 \\
\hline
\end{tabular}

a Yields determined by ${ }^{1} \mathrm{H}-\mathrm{NMR}$ spectroscopy.

Surprisingly, both polymorphic structures exhibited different reactivity at room temperature (compare entries 1-4 and 6-9). This behaviour could be related with the lack of total solubility of both complexes in $\mathrm{MeOH}$ and the consequent maintenance of the crystal structure at room temperature under these conditions. At $40{ }^{\circ} \mathrm{C}$ both species exhibit more similar reactivity maybe because of a higher solubility achieved increasing the temperature (entries 5 and 10). It is remarkable that we performed our reactions in the absence of the commonly used $\mathrm{CH}(\mathrm{OMe})_{3}$, as the source of acetalisation. Its common use is due to the incompatibility of methanol with some Lewis acid catalyst. Fortunately, in our case, this is not a drawback.

After this exploration, and with the optimised reaction conditions in hand, we extended our methodology to a range of different substituted aldehydes as shown in Table 4.

Table 4. Scope of the reaction using catalyst 1.

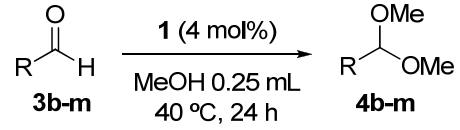

\begin{tabular}{|c|c|c|c|}
\hline Entry & $\mathrm{R}$ & Product & Yield $(\%)^{a}$ \\
\hline 1 & 4-ClPh, 3b & $\mathbf{4 b}^{39}$ & $92(<5)^{d}$ \\
\hline 2 & 3-ClPh, 3c & $4 c^{39}$ & $82(<5)^{d}$ \\
\hline 3 & 4-BrPh, 3d & $\mathbf{4} d^{39}$ & $65(<5)^{d}$ \\
\hline 4 & $4-\mathrm{NO}_{2} \mathrm{Ph}, 3 \mathrm{e}$ & $4 e^{39}$ & $95(<5)^{d}$ \\
\hline 5 & 4-CNPh, $3 f$ & $\mathbf{4} f^{40}$ & $91(<5)^{d}$ \\
\hline $6^{\mathrm{b}}$ & 4-PhPh, 3g & $4 \mathrm{~g}^{41}$ & $52(<5)^{d}$ \\
\hline $7^{c}$ & $\mathrm{Ph}, \mathbf{3 h}$ & $4 h^{39}$ & $72(<5)^{d}$ \\
\hline 8 & 1-Naphthyl, 3i & $4 i^{39}$ & $69(<5)^{d}$ \\
\hline 9 & $\mathrm{PhCH}_{2} \mathrm{CH}_{2}, \mathbf{3 j}$ & $4 j^{39}$ & $>95(<5)^{d}$ \\
\hline 10 & $\mathrm{CH}\left(\mathrm{CH}_{3}\right) \mathrm{CH}_{2} \mathrm{CH}_{2}, \mathbf{3 k}$ & $4 \mathbf{k}^{42}$ & $92(<5)^{d}$ \\
\hline 11 & $t \mathrm{Bu}, \mathbf{3} \mathbf{I}$ & $41^{43}$ & $85(<5)^{d}$ \\
\hline
\end{tabular}

${ }^{a}$ Refers to the yield of crude product. ${ }^{b} 6$ mol\% of catalyst was used. ${ }^{c} 48 \mathrm{~h}$ of reaction. ${ }^{\mathrm{d}}$ Reaction performed in the absence of catalyst.

The reactions took place smoothly giving rise to the desired acetals 4 from moderate to excellent yields. The efficiency of the studied methodology is well accounted since it was successfully applied to all the aldehydes examined 3a-I. Interestingly, no special conditions were needed such as inert atmosphere or dry conditions. It is also remarkable, that the reactions do not work in the absence of catalyst. This is a proof of fact of the efficiency of our catalytic species over the reactivity of the process. The electronic effects on the reactivity were explored using different substituted aromatic 
aldehydes (entries 1-8). It seems that activated aldehydes, with electron-withdrawing groups in their structure, afforded better yields in comparison with non-activated ones (compare entries 1-5 with entries 6-8). Additionally, with aldehydes $3 \mathrm{~g}$ and $3 \mathrm{~h}$, a $6 \mathrm{~mol} \%$ of catalyst or longer reaction times was necessary in order to get moderate yields under the same reaction conditions. Moreover, when using aliphatic aldehydes, a plausible dependence on steric hindrance could be observed (compare entries 9, 10 and 11), since better yields were achieved with a carbonyl group over primary > secondary $>$ tertiary carbon. Although more studies should be necessary to support the mechanism of this process, a tentative route is proposed in Scheme 1.

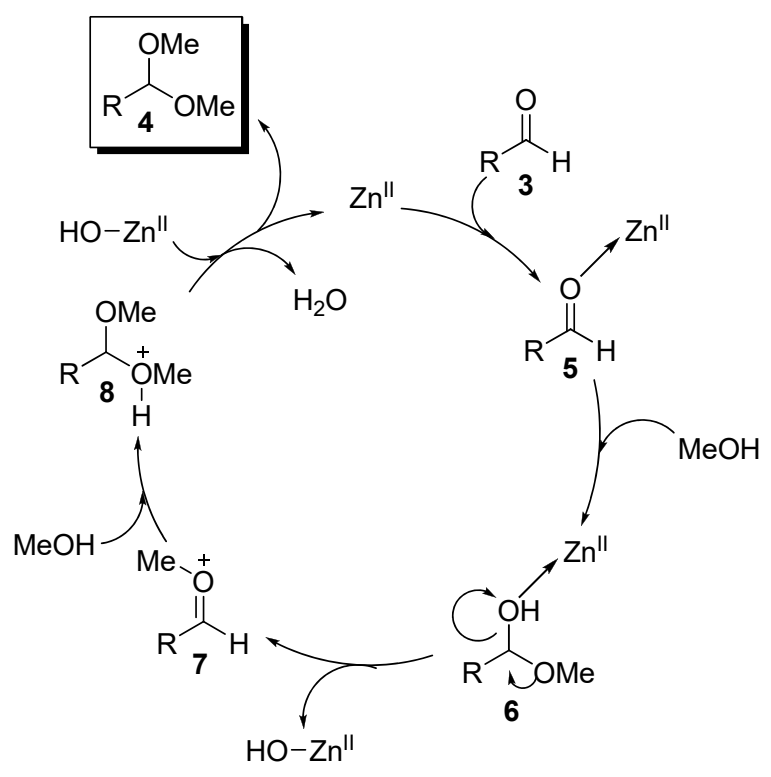

Scheme 1. Plausible reaction mechanism.

In the proposed mechanism depicted in Scheme 1, the aldehyde is first activated by the Lewis acid $\mathrm{Zn}$ (II) catalyst to promote the addition of the first molecule of $\mathrm{MeOH}$ over the intermediate 5 . This attack would produce the hemiacetal $\mathbf{6}$, which evolves to intermediate $\mathbf{7}$ undergoing a subsequent attack of the second molecule of $\mathrm{MeOH}$. Deprotonation of 8 leads to the formation of the acetal $\mathbf{4}$ and releases the catalyst to start a new catalytic cycle. ${ }^{44}$

\section{Conclusions}

In summary, this manuscript details the crystal structures, the thermal stability and the catalytic properties of two polymorphic forms, namely, bis(2-amino-6-methylpyridinium) hexaaquazinc(II) disulfate dehydrate. The crystallisation of both stable forms are favoured under ambient conditions. The crystal structures and the intermolecular interactions rationalise the stability behaviour. Hence, analysis of noncovalent interactions showed a significant role of the hydrogen bonds and $\pi$-stacking in the connections between neighboring chains in $\mathbf{1}$ and $\mathbf{2}$. The new stable forms unveiled that each polymorphic variety has the same chemical composition as well as the thermal behaviours, but presents variations in the internal arrangement of molecules that constitute the crystal lattice. In addition, the polymorphic forms show a supramolecular structure type that possesses a lamellar character. As a result, the interlayer distances are modified according to the nature of the interactions between the different species. In a more pragmatic look, it highlights the energetic difference between the bonds within the inorganic layer and those in between adjacent layers. Additionally, we believe that with these catalytic benchmark examples we demonstrate the capacity of our complexes to act as efficient catalysts in the acetalisation reaction under very mild conditions. Moreover, the use of $\mathrm{MeOH}$ as source of acetalisation, in the absence of the commonly used trimethyl orthoformate, is desirable due to its major availability. ${ }^{45}$ Further catalytic studies are actually ongoing in our laboratory in order to explore additional reactions and will be reported in due course.

\section{Acknowledgements}

Consejo Superior de Investigaciones Científicas (CSIC, PIE2015801010) and Diputación General de Aragón (DGA) (Research Group E-104) are acknowledged for financial support of our research. The authors are grateful to Pr. Abdelmottaleb OUEDERNI for his assistance in TGA/DTA measurements of this study (The Unit of Joint Service of Researche National School of Engineers of Gabes, University of Gabes, Tunisia). The authors thank also the Faculty of Chemistry, University of Wroclaw, Poland for the X-ray measurements of the crystals.

\section{Notes and references}

¥ Crystallographic data for complexes $\mathbf{1}$ and $\mathbf{2}$ are available from the Cambridge Crystallographic Data Centre, with CCDC No. 1039275, for polymorph 1, and No. 1039276 for polymorph 2. Copies of these data can be obtained free of charge from the Cambridge Crystallographic Data Centre, 12 Union Road, Cambridge CB2 1EZ, UK; fax: (+44) 1223-336-033; or e-mail: deposit@ccdc.cam.ac.uk.

1 A. J. Cruz-Cabeza, S. M. Reutzel-Edens and J. Bernstein, Chem. Soc. Rev., 2015, 44, 8619-8635.

2 J. Bernstein in Polymorphism in molecular crystals. Oxford University Press, Oxford, 2002, p. 352.

3 P. Kavuru, S. J. Grebinoski, M. A. Patel, L. Wojtas and K. Chadwick, CrystEngComm, 2016, 18, 1118-1122.

4 R. J. Davey, N. Blagden, G. D. Potts and R. Docherty, J. Am. Chem. Soc., 1997, 119, 1767-1772.

5 I. Weissbuch, M. Lahav and L. Leiserowitz, Cryst. Growth Des., 2003, 3, 125-150.

6 D. H. Arias, J. L. Ryerson, J. D. Cook, N. H. Damrauer and J. C. Johnson, Chem. Sci., 2016, 7, 1185-1191.

7 M. Allesoe, F. Tian, F. Tian, C. Cornett and J. Rantanen, J. Pharm. Sci., 2010, 99, 3711-3718.

8 K. Jarring, T. Larsson, B. Stensland and I. Ymen, J. Pharm. Sci., 2006, 95, 1144-1161.

9 N. Leblanc, M. Allain, N. Mercier and L. Sanguinet, Cryst. Growth Des., 2011, 11, 2064-2069.

10 A. O. Surov, K. A. Solanko, A. D. Bond, A. Bauer-Brandl and G. L. Perlovich, CrystEngComm, 2014, 16, 6603-6611.

11 (a) G. Bolla, S. Mittapalli and A. Nangia, CrystEngComm, 2014, 16, 1-5; (b) C. Butterhof, K. Bärwinkel, J. Senker and J. 
Breu, CrystEngComm, 2012, 14, 6744-6749; (c) A. B. M. Buanz, G. N. Parkinson and S. Gainsford, Cryst. Growth Des., 2011, 11, 1177-1181; (d) S. Skovsgaard and A. D. Bond, CrystEngComm, 2009, 11, 444-453; (e) S. Aitipamula, P. S. Chow and R. B. H. Tan, CrystEngComm, 2009, 11, 18231827; (f) W. W. Porter III, S. C. Elie and A. J. Matzger, Cryst. Growth Des., 2008, 8, 14-16; (g) D. Braga, G. Palladino, M. Polito, K. Rubini, F. Grepioni, M. R. Chierotti and R. Gobetto, Chem. - Eur. J., 2008, 14, 10149-10159.

12 T. Ueto, N. Takata, N. Muroyama, A. Nedu, A. Sasaki, S. Tanida and K. Terada, Cryst. Growth Des., 2012, 12, 485-494.

13 G. Kieslich, S. Kumagai, K. T. Butler, T. Okamura, C. H. Hendon, S. Sun, M. Yamashita, A. Walsh and A. K. Cheetham, Chem. Commun., 2015, 51, 15538-15541.

14 T. Jeeworth, H. L. Wah, K. Bhowon, M. G. Ghoorhoo and D. Babooram, Synth. Read. Inorg. Met.-Org. Chem., 2000, 30, 1023-1038.

15 H. He, L. Jiang, Q. Zhang, Y. Huang, J. -R. Wang and X. Mei, CrystEngComm, 2015, 17, 6566-6574.

16 V. J. Smith, C. G. Marais, K. Suwińska, J. Lipkowski, A. Szumna, C. Esterhuysen and L. J. Barbour, CrystEngComm, 2015, 17, 5129-5133.

17 A. Nangiaa and T. N. Guru Row, CrystEngComm, 2015, 17, 5128.

18 D. Dey and D. Chopra, CrystEngComm, 2015, 17, 52885298.

19 D. Maddileti and A. Nangia, CrystEngComm, 2015, 17, 5252-5265.

20 W. C. McCrone, in Physics and Chemistry of the Organic Solid State (Eds. D. Fox, M. M. Labes and A. Weissberger), WileyInterscience: New York, 1965; Vol. 2, pp 725-767.

21 C. A. Hunter, Chem. Soc. Rev., 1994, 2, 101-109.

22 G. R. Desiraju and T. Steiner, in The weak hydrogen bond in structural chemistry and biology, Oxford University Press: Oxford, 1999.

23 F. H. Allen, V. J. Hoy, J. A. K. Howard, V. R. Thalladi, G. R. Desiraju, C. C. Wilson and G. J. Mclntyre, J. Am. Chem. Soc., 1997, 119, 3477-3480.

24 B. Dolling, A. L. Gillon and A. G. Orpen, Chem. Commun., 2001, 567-568.

25 T. W. Panunto, Z. Urbanczyk-Lipkowska, R. Johnson and M. C. Etter, J. Am. Chem. Soc., 1987, 109, 7786-7797.

26 J. M. A. Robinson, D. Philp, K. D. M. Harris and B. M. Kariuki, New J. Chem., 2000, 24, 799-806.

27 D. Braga, F. Grepioni, L. Maini and M. Polito, Struct. Bond, 2009, 132, 25-50.

28 CrysalisPRO and CrysAlis RED in Xcalibur R software, Agilent Technologies Inc., Yarnton, Oxfordshire, UK.

29 G. M. Sheldrick, SHELXS-97 Programs for Crystal Solution. University of Göttingen, Germany, 1997.

30 G.M. Sheldrick, SHELXL-2013 program for crystal structure refinement. University of Goettingen, Germany, 2013.

31 K. Brandenburg, Diamond. Version 3.2i. Crystal Impact GbR, Bonn, Germany, 2012.

32 D. E. Braun, H. Oberacher, K. Arnhard, M. Orlova and U. J. Griesser, CrystEngComm., DOI: 10.1039/c5ce01758k.

33 T. A. Zeidan, J. T. Trotta, P. A. Tilak, M. A. Oliveira, R. A. Chiarella, B. M. Foxman, Ö. Almarsson and M. B. Hickey, CrystEngComm., DOI: 10.1039/c5ce02467f.

34 F. Hajlaoui, H. Naïli, S. Yahyaoui, M. M. Turnbull, T. Mhiri and T. Bataille, Dalton Trans., 2011, 40, 11613-11620.

35 N. J. Singh, S. K. Min, D. Y. Kim and K. S. Kim, J. Chem. Theory Comput., 2009, 5, 515-529.

36 P. J. Kocieński, Protecting Groups, Thieme, New York, 1994.

37 For some recent and interesting examples using metal catalysts in the acetalisation process, see: (a) N. M. Leonard, M. C. Oswald, D. A. Freiberg, B. A. Nattier, R. C. Smith and R. S. Mohan, J. Org. Chem., 2002, 67, 5202-5207; (b) S. M. Patel, U. V. Chudasama and P. A. Ganesphure, J. Mol. Catal.
A: Chem., 2003, 194, 267-271; (c) R. Kumar and A. K. Chakraborti, Tetrahedron Lett., 2005, 46, 8319-8323; (d) D. B. G. Williams and M. G. Lawton, Green Chem., 2008, 10, 914-917; (e) B. T. Gregg, K. C. Golden and J. F. Quinn, Tetrahedron, 2008, 64, 3287-3295; (f) Z. Miao, L. Xu, H. Song, H. Zhao and L. Chou, Catal. Sci. Technol., 2013, 3, 1942-1954; (g) S. Zhao, Y. Jia and Y.-F. Song, Catal. Sci. Technol., 2014, 4, 2618-2625.

38 A. E. Dear, H. B. Liu, P. A. Mayes and P. Perlmutter, Org. Biomol. Chem., 2006, 4, 3778-3784.

39 S. Ito, A. Hayashi, H. Komai, H. Yamaguchi, Y. Kubota and M. Asami, Tetrahedron, 2011, 67, 2081-2089.

$40 \mathrm{H}$. Langhals, T. Becherer, J. Lindner and A. Obermeier, Eur. J. Org. Chem., 2007, 4328-4336.

41 I. Barba, R. Chinchilla and C. Gomez, Tetrahedron, 1990, 46, 7813-7822.

42 H.-M. Liu, C.-Y. Chang, Y.-C. Lai, M.-D. Yang and C.-Y. Chang, Tetrahedron: Asymmetry, 2014, 25, 187-192.

43 J.-Y. Ortholand, N. Vicart and A. Greiner, J. Org. Chem., 1995, 60, 1880-1884.

44 T. F. Parangi, B. N. Wani and U. V. Chudasama Ind. Eng. Chem. Res., 2013, 52, 8969-8977.

45 (a) K.-i. Shimizu, E. Hayashi, T. Hatamachi, T. Kodama and Y. Kitayama, Tetrahedron Lett., 2004, 45, 5135-5138; (b) Dhakshinamoorthy, M. Alvaro and H. Garcia, Adv. Synth. Catal., 2010, 352, 3022-3030. 